\title{
Engineering Education Certification From the Perspective of Project Management - A Systematic Analysis of Graduation Requirements and Accomplishment
}

\author{
Cheng Xiang \\ Faculty of Life Science and Technology \\ Kunming University of Science and Technology \\ Kunming, China \\ xcheng0871@163.com \\ Lianbing Lin \\ Faculty of Life Science and Technology \\ Kunming University of Science and Technology \\ Kunming, China \\ linlb@sohu.com
}

\author{
Yunjun Li \\ Faculty of Life Science and Technology \\ Kunming University of Science and Technology \\ Kunming, China \\ 595568939@qq.com \\ Xueshan Xia \\ Faculty of Life Science and Technology \\ Kunming University of Science and Technology \\ Kunming, China \\ oliverxia2000@yahoo.com.cn
}

\begin{abstract}
Engineering undergraduate education can be regarded as a four-five-year education project. Engineering education certification is the qualification quality evaluation of the project implementation results. In this paper, from the project management perspective, graduation requirements of certification and the "systematicness" in the evaluation of the achievement degree are analyzed to deepen the theoretical understanding of certification standards. The integrity, hierarchy and relevance of the twelve graduation requirements are expounded, and the systematic concept is applied to solve the problem of the evaluation objects encountered in the graduation achievement evaluation.
\end{abstract}

Keywords-engineering education certification; graduation requirements; project management; systematic

Engineering education certification, one of the important contents of engineering education of "five-in-one" education evaluation system in our country in the new era, is an effective tool to improve the quality of education and also becomes the focus of engineering undergraduate education. Engineering education certification has been fully promoted in our country since China officially became the 18th Member State of the Washington Agreement in June 2, 2016. By the end of 2017, 833 engineering professions in 197 universities have been or will be certified, including all 211 and 985 engineeringoriented colleges [1].

For students, undergraduate education in engineering can be viewed as a four-five-year project that are designed to train students to meet the graduation requirements at their graduation, gain an undergraduate degree in engineering and achieve their goals to become engineering professionals in five years.

Graduation requirements and its achievement evaluation are the core of engineering education certification, which support the realization of training objectives, guide the construction of curriculum system and the design of teaching links, and are the basis of continuous improvement at the same time. The correct understanding of the graduation requirements in the certification standards is of great significance to carry out the certification of engineering education, promote the undergraduate education and learn reforms.

Undergraduate pharmaceutical engineering in Kunming University of Science and Technology received the national engineering education certification respectively in June, 2014 and 2017. On the basis of related concepts of engineering education certification and the practice of engineering certification of pharmaceutical engineering specialty, the setting of graduation requirements and the "systematicness" reflected in the evaluation of the achievement degree are analyzed in this article, aiming to deepen the theoretical understanding of certification standards and provide assistance in carrying out professional certification successfully.

\section{BRIEF INTRODUCTION TO VERSION-2015 GRADUATION REQUIREMENTS IN CHINA'S ENGINEERING EDUCATION CERTIFICATION}

Undergraduate engineering education has a multi-goal feature like other projects. Twelve (12) graduation requirements in the new version of China Engineering Education Certification General Standard can be summarized as: 1 , engineering knowledge; 2 , the problem analysis; 3 , the 
design/development solution; 4, research; 5, the using of modern tools; 6 , engineering and social; 7 , environmental and sustainable development; 8 , professional norms; 9 , individuals and teams; 10, communication; 11, project management; 12 , lifelong learning [2]. Common standards and various professional supplementary standards constitute the graduation requirements of the professional certification.

\section{SYSTEMATIC ANALYSIS OF COMMON STANDARDS OF GRADUATION REQUIREMENTS}

Systematicness is one of the basic concepts of modern project management [3]. Integrity is the most basic and core characteristic and the most centralized manifestation of systematicness [4]. With regard to the specific graduation requirements of the engineering education certification, the graduates will be regarded as complete "humans": not only have the professional knowledge and capacity, but also have the sense of social responsibility and development capabilities that engineering and technical personnel should have. The professional certification graduation requirements on the graduates at the level of "being a man" reflect the humanoriented features. Professor Wei Guo believes graduation requirements 1 to 5 are about "engineering expertise and ability", graduation requirements 6,7 and 8 reflect the requirements on graduates who should have "social responsibility and values", graduation requirements 9, 10 and 12 require graduates to have "comprehensive qualities and development abilities"[5]. The graduation requirements mentioned above constitute the complete requirements on graduates, which reflect the integrity of the project certification.

Hierarchy is also an important feature of systematicness. According to modern project management theories and methods, the hierarchical structure of the system can be expressed clearly by the work breakdown structure (WBS) (Fig 1): students' meeting the graduation requirements and obtaining a degree is the first level of the system. The secondary level of the entire education project can be divided into two aspects: first, the overall quality of being a man, i.e., graduates should have a healthy body, spirit and virtues, are able to adapt to social and natural environment, to survive and develop in the coming work and life, including the graduation requirements from 6 to 12; second, the engineering knowledge and ability, i.e., graduates should be professional knowledge and have abilities to solve modern complex engineering problems, including graduation requirements from 1 to 5 . Twelve graduation requirements are as the third level, a refinement of the contents of the previous level. To further break down the system, each graduation requirement can be broken into a fourth level of the system - the indexes. The fifth level is to achieve the important teaching activities involved in each index point, such as organic chemistry, chemical engineering, pharmaceutical chemistry, pharmaceutical technology and other core courses, etc..

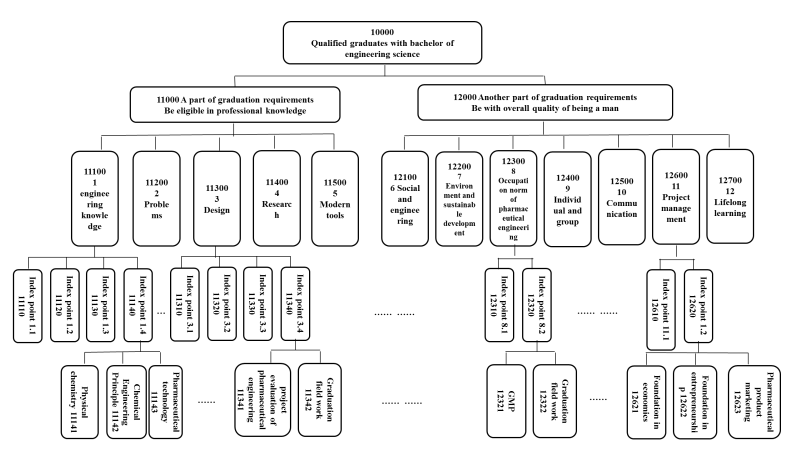

Fig. 1. Construction decomposition of graduation requirements in pharmaceutical engineering

Twelve pieces in the system of graduation requirements are not independent, but organically integrated, reflecting the interrelated characteristics of the various elements of systematicness. In accordance with the solution to complex engineering issues which are viewed as a clue, the relationship between the twelve graduation requirements can be shown in Fig. 2. Faced with the modern engineering projects, Professor Zhang thinks that graduates should be able to answer the questions of "will or won't" (graduation requirement 1, 2, 3, 4, 5 ), "can or can't" (graduation requirement 7and 8), "should or shouldn't" (graduation requirements 8), "worth or not" (graduation requirement 11), "with or without modern ability" (graduation requirement 9, 10, 11) and other issues [6]. The graduation requirements of knowledge and ability can be integrated in the realization of complex engineering problems within the system. In addition, the requirements of graduation for engineering expertise and quality are interlinked. For example, graduation requirement 3 "design/development solutions" requiring "consideration of social, health, safety, legal, cultural and environmental factors" is to consider the influence of social and natural environment on the project while the graduation requirement 6 and 7 are respectively related to the influences of the implementation of the project on the social and natural environment. The requirement 3, 6 and 7 constitute action and reaction force from a different perspective to consider stakeholder relations in modern project management. For another example, the graduation requirement 2 "identification and expression of complex engineering problems" and the graduation requirement 10 "smooth and accurate communication" constitute the ability to communicate with clients together and put forward the solution (graduation requirement 3). Furthermore, graduation requirement 8 about professional ethics is further professional norms built on the basis of the observance of social laws and morality. Project management (graduate requirement 11), teamwork (graduation requirement 9) and lifelong learning (graduation requirement 12) are the humanistic qualifications necessary to complete the complex project of modern pharmaceutical engineering. 


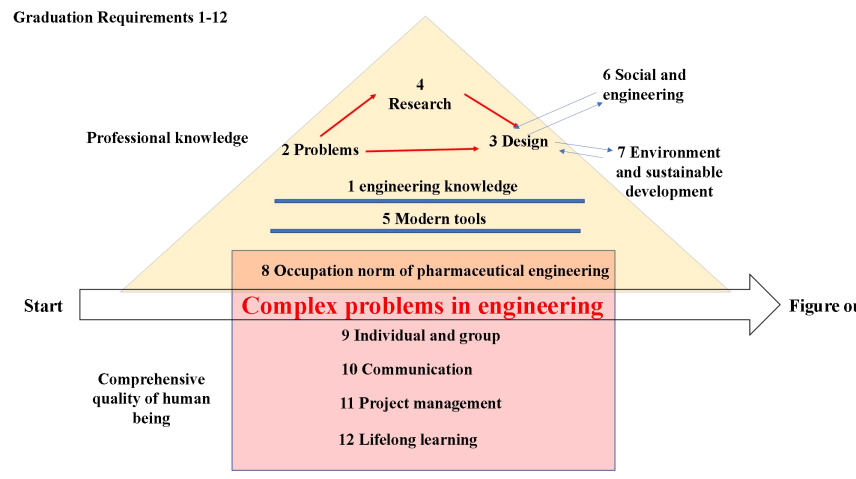

Fig. 2. Relations between 12 graduation requirements in engineering education accreditation

The five graduation requirements for engineering expertise and competence modules also constitute an organic subsystem with strong logical connections. Graduation Requirement 1 is to solve the knowledge base of modern engineering, such as chemical principles, pharmaceutical chemistry and pharmacy, which is the cornerstone to solve complex pharmaceutical engineering problems. Graduation requirement 2 is the beginning of the modern project, i.e., putting forward and recognizing the engineering problem by analyzing the situation clearly, or decomposing the complex engineering problem into a few relatively easy and crucial problems through literature review. Graduation requirement 3 is the implementation process to design and solve complex engineering problems under control of the economic, social, natural environment and many other things. Graduation requirement 4 is researching and analyzing the difficulties of complex engineering problems. For pharmaceutical engineering, not only laboratory-scale pharmaceutical chemistry experiments, pharmaceutical experiments are included, but also pilot-scale pharmaceutical engineering comprehensive experiments are needed to be completed. The conclusions drawn are to support the solution design and optimization for the pharmaceutical project. Graduation requirements 5 is necessary tools to design and implement a project, such as computer graphics, scientific literature retrieval and instrumental analysis in pharmaceutical engineering, which runs through the execution of modern pharmaceutical engineering projects. The above graduation requirements constitute a more complete subsystem.

It can be seen that the common standards of 12 graduation requirements of engineering education certification requires reflect that they are centered on by graduates' abilities and qualities, the core to solve the complex engineering problems, and of obvious systematicness.

\section{SYSTEMATIC ANALYSIS OF THE EVALUATION PROGRESS OF THE ACHIEVEMENT DEGREE OF GRADUATION REQUIREMENTS}

The evaluation of achievement degree of graduation requirements is the key activity of quality control in engineering education project. In 2014, we conducted the evaluation of achievement degree of graduation requirements for the first time. The evaluation mechanism and the qualitative and quantitative evaluation method for the achievement degree of graduation requirements have been preliminarily established, which are similar to the later articles [7-9]. In the recertification in 2017, we used third-party evaluation, employers' evaluation and graduates' evaluation to improve the composition of the evaluation system. For different indicators, we offer different thresholds to avoid using the standard, according to the common standards of 12 graduation requirements at the same time.

However, we encountered some controversy in the evaluation of the achievement degree of graduation requirements involving in the principle of the evaluation of achievement degree of graduation requirements evaluation. We need to think and discuss from the systematic perspective of engineering education.

\section{A. Determination of system scope}

The system scope of the object to be assessed, namely, "which group of students should be evaluated?" In 2014, we adopted the method of "calculating the minimum value of the degree of curriculum attainment in the recent two years" to calculate the degree of the courses. This method was not only the same as that used by Guilin University of Technology but also was recognized by the certification committee in 2014, and the object of the evaluation was the current training programs.

However, in the recertification process in 2017, we realized that "students in the last two years" included four grades from 2012 to 2016. The selection of such evaluation objects led to the misuse of the students' achievements and violated the basic concept of "being a complete person" in the category of being appraised. Therefore, in the re-certification in 2017, we improved the accredited subjects. Based on the grade 2012 students (graduated in 2016) who graduated in the recent year, we fully evaluated the results of their four-year university studies and reflected the basic idea of complete systematicness, which had been affirmed by the certification committee.

However, there is some controversy regarding the 2012 graduates as the evaluation targets, because the training program version 2009 was implemented for the grade 2012 students while the current training program is version 2013. Was it reasonable to evaluate the discontinued training program by current training program evaluation system? In our opinion, the relationship of the evaluation of the achievement degree of graduation requirements and continuous improvement are that between supervision and feedback while the feedback itself is always delayed. One of the core concepts of engineering education certification is "Substantially Equivalent" at the same time, which does not stress on what courses are offered in the training program. The key is whether the knowledge, abilities and qualities required by engineering professionals have been reached fully and whether the common standards of the achievement degree of graduation requirements and supplementary standards are met. Therefore, it is reasonable to use the current evaluation rules to evaluate the previous training programs. 


\section{B. Property of the achievement degree of graduation requirements}

It is an issue that the achievement degree of graduation requirements is a partial evaluation or a comprehensive evaluation. At the time of initial certification in 2014, we only evaluated the graduation requirement 7 at that time, illustrating the establishment of our evaluation mechanism and method. However, as previously analyzed, the twelve graduation requirements constitute a complete system of knowledge, abilities and qualifications that an undergraduate graduate in engineering should possess and cannot be divided. Therefore, in accordance with the basic concept of "systematicness", in the recertification process in 2017 we evaluated the Grade-2012 graduates according to all the graduation requirements.

Another aspect of this issue is whether there is a necessity to evaluate all the curricula in the training program, which has caused some controversy. From 2014 to early 2017, some teachers thought that all the courses in the training program should support specific graduation requirements; otherwise there would be no point in opening these courses. Without an assessment of achievement degree of graduation requirements for each course, there would be short of supervision of the courses excluding in the evaluation system. However, the certification committee considered that courses for the evaluation of the achievement degree of graduation requirements should be no more than 5 courses and the graduation requirements for each course should be 3-4 points. Then contradiction was formed between the whole and the part in the system. How to resolve this conflict? First of all, it should be recognized that a course can support a number of graduation requirements and their indicators, especially in such a comprehensive link as graduation design project (dissertation) which is a comprehensive embodiment of the undergraduate engineering teaching results. With the reform of undergraduate education programs in engineering major, there will be fewer and fewer credits in training programs, fewer and fewer courses offered and more and more goals to be undertaken in each course. For modern projects, it is also necessary for courses to solve complex engineering problems. Therefore, the number of graduation requirements for the course support should not be limited. A course should be encouraged to support more graduation requirements. Through clarifying the courses whether the graduation requirements are met, the quality of teaching and the continuous improvement of the curriculum can be promoted. On the other hand, the core contents of the evaluation of the achievement degree of graduation requirement should be the knowledge, ability and accomplishment obtained by students after study, rather than the knowledge points of a certain course. Therefore, the content of education as a carrier of the course can be properly replaced, that is to say, the teaching steering committee can choose 2-4 courses from multiple courses that support the same graduation point requirements. The required knowledge, abilities and qualifications which needed to cover the graduation requirements are set according to the course weight of the graduation requirements. The information on evaluation value, calculation, evaluation index points and the whole degree of achievement of graduation requirements is collected for the evaluation of the achievement of graduation requirements. In short, the graduation requirements of the course support points can be multiple, without limitation. The overall of achievement degree of graduation requirements can be assessed by the teaching steering committee that can draw the achieved indexes of some courses based on the weight coefficient in the way of qualitative and quantitative evaluation.

\section{SUMMARY}

Undergraduate engineering education is a four-five-year education program, and engineering education certification is the implementation of the project qualified quality certification. The graduation requirements for engineering education certification reflect the systematicness of education programs. In the process of the evaluation of the achievement degree of graduation requirements, the concept of systematic evaluation can be grasped to make it clear that graduates are the object of graduation assessment and are the result of comprehensive literacy and engineering professional knowledge and ability formed in their complete undergraduate study.

In the future continuous improvement, the evaluation object should be more specific to each graduate, rather than the average values of all students, which is more accurate. The emphasis of the evaluation is shifted from teaching the knowledge points of courses to the ability and quality of the students after they are educated so as to promote the sustainable development after their graduation.

\section{REFERENCES}

[1] Yan Wu. "Grasp the'six new' certification, construction of first-class undergraduate", 2017 third phase of engineering education certification professional training, China Engineering Education Certification Association,2017.1. Kunming, Yunnan. (In Chinese)

[2] General Standard. China Engineering Education Professional Certification,Association .http://www.ceeaa.org.cn/main!newsList4Top. w?menuID=01010702(In Chinese)

[3] Lijuan Liu, Qiang Wang. "Modern project management (Fourth edition".Shanghai University of Finance and Economics Press,2016, pp.18-22. (In Chinese)

[4] Yingluo Wang. "System Engineering.Fourth edition". Machinery Industry Press, 2008, pp.6. (In Chinese)

[5] Guo Wei. "Preparation of graduation requirements decomposition and implementation", 2017 third phase of engineering education certification professional training, China Engineering Education Certification Association,2017.1. Kunming, Yunnan. (In Chinese)

[6] Xingcheng Zhang. "Understand deeply the conception of authentication, promote the professional construction and reform", 2017 third phase of engineering education certification professional training, China Engineering Education Certification Association,2017.1. Kunming, Yunnan.(In Chinese)

[7] Xiangsheng Gao, Tao Jiu, Min Wang. "Engineering education certification graduation requirements to achieve a degree of evaluation methods and steps". Education and Teaching Forum, 2016,vol51, pp.206-208. (In Chinese)

[8] YuefeiWang, Bing Huang, Xuhui Sun,etc. "Research on the Quantitative Evaluation of the Graduation Requirements of Industrial Engineering". Technology horizon, 2016,26,pp.88-89. (In Chinese)

[9] Ningjie Li, Qinglin Xie, Liangliang Huang. "Consideration on the Process of Formulating and Evaluating Graduation Requirements of Environmental Engineering Based on the 2015 Edition of Engineering Education Certification Standard". Education and Teaching Forum, 2017,vol8,pp.205-206. (In Chinese) 